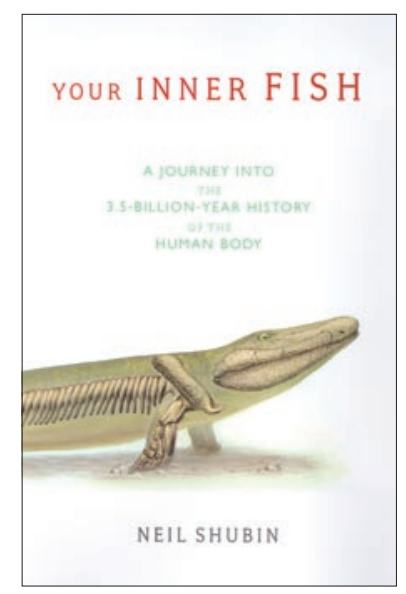

\section{Your inner fish}

\section{A journey into the 3.5-billion-year history of the human body}

Neil Shubin

Pantheon Books. New York, New York, USA. 2008.

240 pp. \$24.00. ISBN: 978-0-375-42447-2 (hardcover).

\section{Reviewed by Jennifer A. Clack}

University Museum of Zoology, Cambridge, United Kingdom.

E-mail: j.a.clack@zoo.cam.ac.uk once heard of a medical doctor who "didn't believe in evolution" because he "could not see the connection between a human and a giraffe." In Your inner fish, University of Chicago paleontologist Neil Shubin combines information from the worlds of paleontology, embryology, and developmental genetics to explain the evolutionary connection not only between humans and giraffes (that is to say, all other mammals) but also between ourselves and all vertebrates and indeed nonvertebrates too.

Written largely in the first person, this lively and convincing account begins with an exposition of the logic underlying the fields of anatomy and stratigraphy (geological study of the stratification of sediment and rock) mixed with Shubin's experiences of the terrors and triumphs of paleontological field work. I empathize with those descriptions, which illustrate the serendipitous nature of finding fossils and also the predictability that is possible when researchers have done their homework. Shubin describes the magic of anatomical dissection and the fundamental homologies among limbs of different vertebrates. Shubin and colleagues have contributed much to our understanding of the origin of vertebrate limbs with digits. In 2006, Shubin's group reported their discovery of a fossilized Tiktaalik skeleton in northern Canada. This fish, with fins possessing basic wristlike joints that could support the front of the body out of water, is believed to be a transitional animal whose existence partly bridges the gaps in our understanding of the emergence of tetrapods (four-legged animals) from their fish ancestors.

Subsequent chapters focus on the history of discoveries of the embryonic origins and genetic control mechanisms at work in different regions of the body. This historical background brings home to the reader that science is performed by people in the context of their times. Shubin's description of patterns common in the development of appendages, teeth, the vertebrate head, body plans, and sensory systems are extolled with quirky and little-known facts that add interest and intrigue. More deeply, he reveals the connections between humans and multicellular organisms at the cellular and molecular levels and the relationship of those connections to features prefigured in unicellular organisms.

In the last chapter, which expounds the logic of phylogenetic analysis, the author's explanation of sets within sets and how cladistic methodology (classification of organisms by common ancestry) works to produce a phylogeny is unclear and may be confusing for nonspecialist readers.

Some minor mistakes and omissions detract from the overall appeal of the book. More substantially, the role played by Acanthostega - an extinct tetrapod and among the first vertebrate animals to have recognizable limbs - is played down, whereas it was a key to unlocking this field. While Shubin mentions earlier that this genus displayed a primitive, flipper-like limb, he fails to mention the astonishing fact (at the time of its discovery) that it possessed eight digits per limb and that this, among other factors, initiated a revolution in the way the origin of limbs was viewed.

Additionally, and also to relegate the significance of Acanthostega, Shubin uses an old reconstruction of Ichthyostega (another early tetrapod genus contemporary with Acanthostega) to illustrate a Devonian tetrapod, when this is known to be substantially incorrect. There are good reconstructions of Acanthostega that would have provided a better model. This is also the case in a later chapter on ears, in which Ichthyostega is again used to illustrate an early tetrapod, when its ear is known to be highly unrepresentative of any other early tetrapod ear. Acanthostega is well known in this regard and should have been used. I was also surprised to find no mention of Michael Coates, a fellow professor at the University of Chicago who did much of the key work on Acanthostega and is now working in Shubin's lab, nor of Shubin's postdoctoral mentor, the late Pere Alberch, with whom Shubin did some key embryological work.

Most surprising of all is the lack of any mention of the importance of neural crest cell populations in the development of vertebrates, in particular the evolution of the head, jaws, sense organs, and dermal skeleton, the latter two apparently intimately connected in their origins from neural crest ectodermal tissues. The reason may be that it is one of those issues that is so much at the heart of things that it gets taken for granted by those in the field.

Despite some of my disagreements with statements made in this book, I recommend it for anyone who wants a userfriendly guide to the concepts underlying the evolution of animals, including humans, and especially to those readers who are unclear about the basis for ideas about organic evolution and who would like to know more about what connects us to the rest of the animal kingdom and indeed the rest of the organic world. It's an exciting, sometimes breathless read in an accessible style, though the more staid might find the tone grating. I will, despite some reservations, put it on the reading list for students studying vertebrate biology. 